\title{
Cells Contrive and Construction for Biological Activities Representation - An Image Based Approach
}

\author{
Jayanthi Manicassamy and P. Dhavachelvan \\ Department of Computer Science, Pondicherry University, Pondicherry, India.
}

\begin{abstract}
In organisms cells are conscientious for all functional behavior in biological systems that react externally. Networked cells with communication through image based representation, is utterly a novel technique to systematize or organize roles of cells. Molecules under lie the bases for behaviors of cells. Images duplicate the manner in which humans perceive and understand objects. Pictographic syntheses of real or imaginary objects from computer-based models are highly reliable mode of conveying informations than any other modes of conveying. In this perspective in this paper, theoretical narration about the task that is to be carried out further for representing biological activities that have been conveyed. New discovery made through research in biological systems could be globally obtainable by researches as a base for their research development. It would help users to afford exhaustive information about cells interact and its reactivity in the whole system both by internal and external means by graphical means. Apart from this, in this paper significance of image based representation cells contrive and construction in system have been represented that would provide a way for advanced research in drug discovery and in disease identification.
\end{abstract}

The full text of the article is not available in the cache. Kindly refer the IJCA digital library at www.ijcaonline.org for the complete article. In case, you face problems while downloading the full-text, please send a mail to editor at editor@ijcaonline.org 